\title{
Goodbye, Jo
}

Cite as: CMAJ 2017 August 28;189:E1094-5. doi: 10.1503/cmaj.161384

ou dreamt of Georgina last night. You saw her sitting in a purple chair that backed up against the waiting room windows. She was chattering with someone in the room, waving her knobby hands in the air as she laughed. Classic Georgina - or Jo, as you called her. You don't remember when she told you to call her that; you just know that she did. In the presence of others, she'd address you professionally, but when no one else was around, she'd call you by your first name something she had started on her own, but only after many blood pressure checks and chest examinations. In your dream, she turns to look up at you, white bob cropped short, silver earrings like lacy spiders clipped to her large lobes, and says to you, "You pregnant again, doc?"

You waken and think of her. How long has she been coughing? You prescribe inhalers, treat the occasional pneumonia and warn her (oh, the exhortations) about smoking. When she asks - never complains - about the pain in her joints, you prescribe the usual anti-inflammatories and topical rubs.

"We need to watch your blood pressure on these meds, Jo. They can be hard on your stomach and kidneys."

"Whatever you say, doc - I don't mind. I'm a good patient."

You two go a long way back. In the early days, there were visits to the little grey bungalow on the dirt road in Ballantrae.

"I'll come to see Russ," you'd say.

"That would be great, Gwen."

There they would be, sitting in the darkened kitchen, waiting for you - Jo and her beloved spouse. Was the linoleum blue? You would talk about golf, make sure he was comfortable, then reassure him that you would come again soon.

"Thank you kindly," Russ would say. Then Jo would follow you out to the gravel laneway. She'd cry. You'd put your arm around her and you knew the whole family

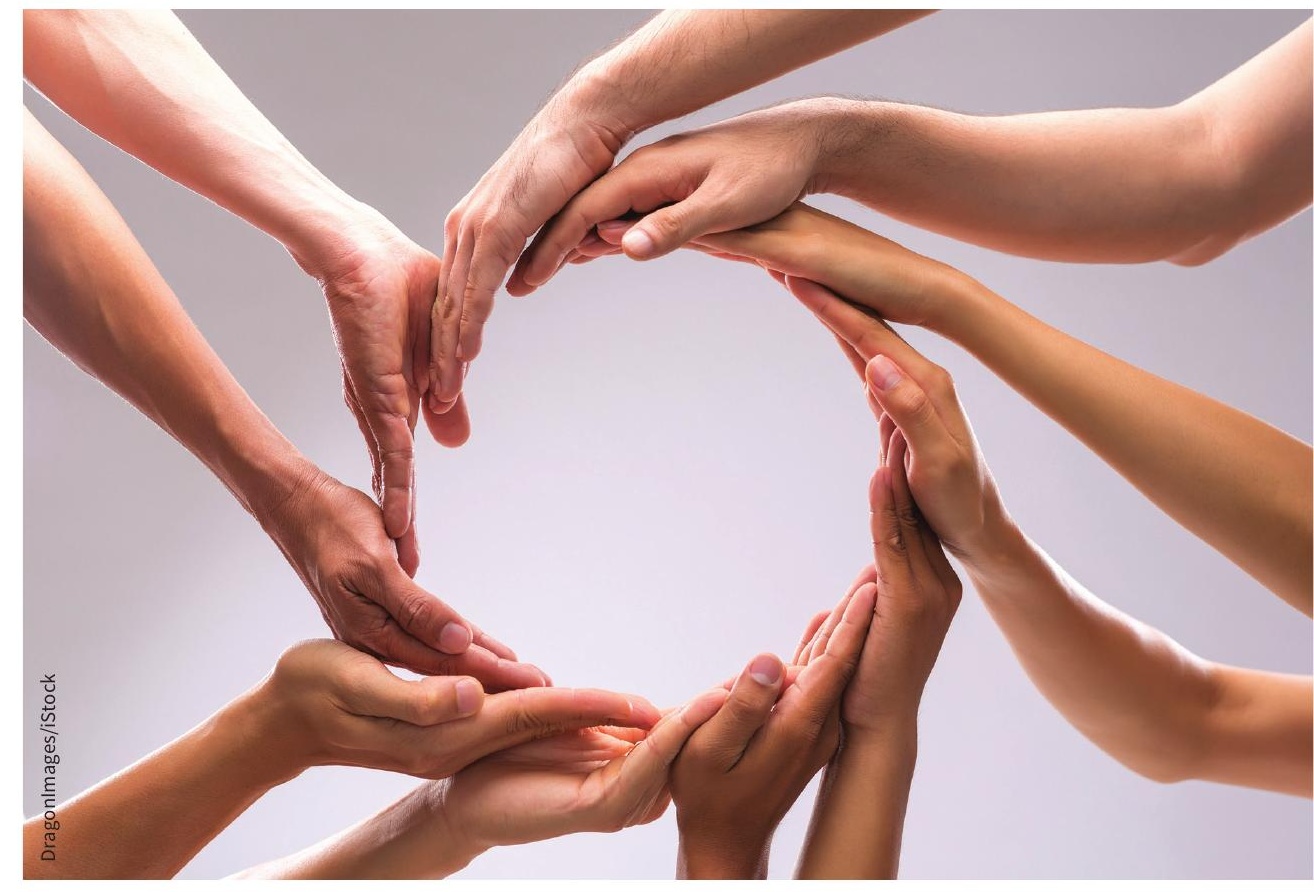

would be comforted. Jo would share whatever you had done for her with all of them. You knew of all of them because Jo had bragged on each one. There were the burdens and concerns of any mother and grandmother, yet she had a tenderness and a generosity that extended beyond her health and finances. She has shared some of that with you.

"Jo, you didn't need to buy the baby anything. You really have been too kind."

"Did you like the little sleeper, doc? Thought you'd like it. Pink for a baby girl."

Her cough has worsened. Sometimes chest $x$-rays get it wrong, but rarely the $\mathrm{CT}$ scans. The surgery is scheduled, part of the lung comes out, and Jo declares that she will get through it.

"I'm a good patient, doc. Everyone likes me at the hospital. I even make the nurses laugh. The surgeon told me he got it all."

You track her weights, her breathing, her blood pressure. The letters come from the consultants. Things look good. Jo seems strong, and after a few weeks, she plans on attending a church social.

"Well done, Jo; you are an inspiration to me. Honestly, you're like the Duracell bunny: you just keep going."

There is something about the grin of this four-foot-nothing woman. She is faithful with her visits, never late, never misses an appointment. She reminds you to keep checking her chest. You know it is at the back of both of your minds, but she never speaks openly of her fears. The big "C" becomes a part of the unspoken agenda. You both understand there will be a routine to follow, as if ritual will keep it in abeyance. You begin to hope that surveillance can outsmart recurrence. Thinking ahead becomes more than just early screening. It's a superstitious tactic: if followed meticulously enough, it will be like setting a trap for a rat and then hoping the rat knows about it and decides not to return. 
But surveillance isn't magic - it's just surveillance. One day, more shadows, in another lung. There are no surgical options. You and Jo discuss radiation.

"I know there is no cure. It just puts things off longer, and I'm OK with that. I've talked it over with my family and this is what I want to do."

You agree. You ask if she wants you to call her son, Lloyd, but she says no.

"In hindsight" is such a cliché. It's a saying that lets you off the hook for what you could not see or did not want to see.

Jo is more stooped after her radiation treatments. She uses a cane to get down the hall. Her lavender pants are pulled high up her waist and she has an angel from Avon clipped to the lapel of her flowered blouse.

"I've got a really bad cough now, doc. They told me to expect it. It's from the radiation. They gave me cough medicine, but it's not doing any good."

Not much does any good. This is the long, dark hallway, when you do the best you can, but there is no happy fix. You are out of the office for a few days. In hindsight, you tell yourself you are allowed. It might have been a conference or business with the university, but it doesn't matter. One of your secretaries tells you that Georgina was in and, for the first time ever, complained at the desk about how long it was taking to be seen.

"We put her in with the resident doctor till you were back, but honestly, I have never seen her like that."

Excruciating pain in her thigh. X-ray suggests a mass; bone scan confirms something is eating away at her femur. You fax the report to her oncologist. You call Jo. Why is she not surprised? She is thankful for the morphine.

"I've come to you for a long time. It's not like me to speak to the staff that way. You know that. I just had so much pain. I wanted you, but you were away and I didn't know what to do."

You tell her she did the right thing. She tells you the oncologist called her and wants to radiate her thigh to shrink the mass.
This little bit of a thing gets her leg radiated on a regular basis. Her treatments are time-consuming, so you talk to her by phone. It hardly seems possible, but for a few weeks, you lose track of her.

The next news of Jo is an admission notice from the local hospital: pathological fracture. Her femur snaps at the site of the tumour. She declines any more interventions and then, one day, she just up and dies. Just like that, she is gone, and for you, there are more things that would have been said. Right enough she belongs to her family, but somehow she belongs to you. You call and leave condolences on Lloyd's answering machine. This is it, then.

\section{Gweneth Sampson MD MScCH}

Assistant Professor, Faculty of Medicine, University of Toronto, Toronto, Ont.

This article has been peer reviewed.

This is a true story. The family gave their consent for this story to be told. 